\title{
Improved Primers for the Specific Detection of Leifsonia xyli subsp. xyli in Sugarcane Using a Conventional PCR Assay
}

\author{
Sheng-Ren Sun', Jun-Lü Chen ${ }^{1,2}$, Yao-Yao Duan', Na Chu', Mei-Ting Huang ${ }^{1}$, Hua-Ying Fu', and San-Ji Gao ${ }^{1, \dagger}$ \\ ${ }^{1}$ National Engineering Research Center for Sugarcane, Fujian Agriculture and Forestry University, Fuzhou, Fujian 350002, \\ China \\ ${ }^{2}$ Guangdong Provincial Bioengineering Institute (Guangzhou Sugarcane Industry Research Institute), Guangzhou, Guangdong \\ 510316, China
}

\begin{abstract}
Ratoon stunting disease (RSD), one of the most important diseases of sugarcane, is caused by the bacterium Leifsonia xyli subsp. xyli $(L x x)$. $L x x$ infects sugarcane worldwide and RSD results in high yield losses and varietal degeneration. It is highly challenging to diagnose RSD based on visual symptomatology because this disease does not exhibit distinct external and internal symptoms. In this study, a novel $L x x$-specific primer pair Lxx-F1/Lxx-R1 was designed to detect this pathogen using a conventional PCR assay. These primers were then compared with four published $L x x$-specific primers and one universal Leifsonia generic primer pair LayF/LayR. Sugarcane leaf samples were collected from Saccharum spp. hybrids in commercial fields (315 samples) and from germplasm clones of five Saccharum species and Erianthus arundinaceus (216 samples). These samples were used for comparative field diagnosis with

CxxITSr\#5 and had 10-fold higher sensitivity than the primer pairs Pat1-F2/Pat1-R2, LayF/LayR, and C2F/C2R. Comparison of PCR assays revealed that natural $L x x$-infection incidence $(6.1 \%)$ in field sample evaluation identified by Lxx-F1/Lxx-R1 primers was higher than incidences $(0.7$ to $3.0 \%$ ) determined by other primer pairs. Moreover, no nonspecific DNA amplification occurred within these field samples with Lxx-F1/Lxx-R1 primers, unlike with the primer pairs $\mathrm{Cxx} 1 / \mathrm{Cxx} 2$ and LayF/LayR. Diverse Leifsonia strains were identified by PCR detection with LayF/LayR primers in the field samples, whereas whether these Leifsonia strains were pathogenic to sugarcane requires further research. Our investigations revealed that the PCR assay with the newly designed primers Lxx-F1/Lxx-R1 could be widely used for RSD diagnosis and $L x x$-pathogen detection with satisfactory sensitivity and specificity.
\end{abstract} six conventional PCR assays. Sensitivity tests suggested that the PCR assay with primers Lxx-F1/Lxx-R1 had the same detection limit (1 pg of $L x x$ genomic DNA) as the primer pairs $C x x 1 / C x \times 2$ and CxxITSf\#5/
Keywords: Leifsonia xyli subsp. xyli, polymerase chain reaction (PCR), molecular detection, ratoon stunting disease (RSD), sugarcane
Ratoon stunting disease (RSD) was identified as early as 1944-1945 in Queensland, Australia, from sugarcane cultivar Q28, and is now considered one of the most destructive sugarcane diseases around the world, including in China (Gao et al. 2008; Gillaspie and Teakle 1989; Martin et al. 1982). The disease is caused by a grampositive coryneform bacterium, formerly identified as Clavibacter xyli subsp. xyli $(C x x)$, that colonizes the xylem vessels of the sugarcane plant (Davis et al. 1984); subsequently, the causal agent was identified as Leifsonia xyli subsp. xyli $(L x x)$ based on bacterial rRNA gene attributes (Evtushenko et al. 2000). Sugarcane plants with $L x x$ infection commonly exhibit reduced stalk height (stunting), stalk diameter, number of tillers, and decreased ratooning ability. RSD can cause 12 to $37 \%$ yield losses under normal conditions and up to $60 \%$ losses under additional drought stress conditions (Gillaspie and Teakle 1989). The $L x x$ pathogen is transmitted by propagating diseased plant cuttings from field to field and by using harvesting tools among plants within a field (Gillaspie and Teakle 1989; Mills et al. 2001). It is generally accepted that sugarcane is the only natural host of Lxx (Zavaglia et al. 2016). RSD is effectively controlled by integrated disease management, namely, a combination of

${ }^{\dagger}$ Corresponding author: S.-J. Gao; gaosanji@yahoo.com

Funding: This work was supported by an Earmark Fund from the China Agriculture Research System (CARS-170302).

*The $\boldsymbol{e}$-Xtra logo stands for "electronic extra" and indicates that two supplementary tables and two supplementary figures are published online.

The author(s) declare no conflict of interest.

Accepted for publication 9 June 2019.

(C) 2019 The American Phytopathological Society tissue culture, hot water treatment $\left(50^{\circ} \mathrm{C}\right.$ for 2 to $\left.3 \mathrm{~h}\right)$, internal and external quarantine, and use of resistant varieties (Farahani et al. 2015; Gillaspie and Teakle 1989).

It is very difficult to diagnose RSD based on visual inspection since there is a lack of typical external symptoms and because of the ambiguous nature of the internal symptoms (Gillaspie and Teakle 1989). The techniques used for RSD detection and identification mainly include microscopy inspection, serological tests, and DNA-based molecular detection. As early as the 1980s, alkaline-induced metaxylem auto fluorescence (AIMA) and phase contrast microscopy (PCM) were commonly used to detect and identify $L x x$ for RSD diagnosis, but both lacked sufficient sensitivity or accuracy and were time- and laborintensive (Hoy et al. 1999; Taylor et al. 2003). The causal pathogen Lxx was successfully isolated by Davis et al. (1984), facilitating the development of diverse serological reaction assays, such as dot blot enzyme immunoassays (DB-EIA), evaporative binding enzyme immunoassays (EB-EIA), tissue blot enzyme immunoassays (TB-EIA), and enzyme linked immunosorbent assays (ELISA) (Comstock et al. 1996; Davis et al. 1994; Harrison and Davis 1990; Hoy et al. 1999; Matthews 1993). These immunological techniques were widely used for high-throughput diagnosis of RSD in the field but were less sensitive or accurate and required tedious and complicated procedures (Taylor et al. 2003; Young et al. 2016). Moreover, the serological tests and microscopy inspection are not capable of differentiating Lxx from L. xyli subsp. cynodontis (Lxc) or L. xyli-like bacteria that may not be pathogenic to sugarcane (Taylor et al. 2003).

Since the 1990s, numerous polymerase chain reaction (PCR) assays were reported for $L x x$ detection using different pairs of primers. One pair of primers, Cxx1 and Cxx2 (Pan et al. 1998), and another pair of primers, CxxITSf5\# and CxxITSr5\# (Fegan et al. 1998), were developed to target the internal transcribed spacer (ITS) region of 16S-23S ribosomal RNA (rRNA). Recently, one universal pair of primers, LayF/LayR, targeting the ITS region was designed to amplify Leifsonia strains (Young and Nock 2017). Additionally, three 
pairs of $L x x$ specific primers C2F/C2R (Taylor et al. 2003), Pat1-F2/ Pat1-R2 (Fu et al. 2016), and FL12650F2/FL12650R2 (Zavaglia et al. 2016) were designed to target unique genes or gene fragments in the $L x x$ genome to detect this pathogen. Quicker and more sensitive assays, nested-PCR (Farahani et al. 2015; Shen et al. 2012), realtime quantitative PCR (qPCR) (Carvalho et al. 2016; Fu et al. 2016; Grisham et al. 2007; Pelosi et al. 2013; Young et al. 2016), and loopmediated isothermal amplification (LAMP) (Ghai et al. 2014; Liu et al. 2013; Wu et al. 2018), were also developed and used for diagnosis of RSD. However, PCR-based assays are still more widely used for $L x x$ detection at the large scale of field samples with the advantages of lower cost and convenient processes.

To date, the reported PCR assays with individual primer pairs had various shortcomings in detecting $L x x$, such as unsatisfactory sensitivity or occurrence of nonspecific amplification, particularly for Cxx1 and Cxx2 primers during our routine testing of sugarcane for RSD. Thus, in this study we tried to achieve four objectives: (1) develop a novel primer pair (Lxx-F1 and Lxx-R1) and PCR procedure for more efficient and reliable detection of $L x x$; (2) compare the performance of PCR assays using five published primer pairs and our newly developed primer pair in numerous sugarcane leaf samples from fields; (3) illustrate the reasons for occurrence of nonspecific amplification by PCR methods with $\mathrm{Cxx} 1 / \mathrm{Cxx} 2$ and LayF/LayR primers through cloning and sequencing of amplified PCR products; and (4) identify the other bacteria of Leifsonia strains found in sugarcane leaves.

\section{Materials and Methods}

Leaf sample collection. From 2016 to 2018, a set of 315 sugarcane leaf samples (one leaf per clone in each field) was collected from clones or varieties of Saccharum spp. hybrids in commercial sugarcane-planting fields in Yunnan, Guizhou, and Sichuan provinces, China. Another set of 216 sugarcane leaf samples (six leaves per clone) was collected from clones of Saccharum species (S. barberi, S. officinarum, S. robustum, S. sinense, and S. spontaneum) and from $E$. arundinaceus in the sugarcane germplasm nursery in Sanya, Hainan province in China. $L x x$-free leaf samples from Saccharum spp. clones FN09-12206 and FN11-2097 were used as negative controls during PCR detection for $L x x$. All leaf samples were rinsed with $75 \%$ ethanol and stored at $-80^{\circ} \mathrm{C}$ before DNA extraction.

Bacterial strains of the genus Leifsonia. Seven bacterial strains in the genus Leifsonia were used for specificity tests of primers, including $L$. ginsengi ACCC 11169, L. poae ACCC 01116, and $L$. rubra DSM 15304 bought from the China General Microbiological Culture Collection Center (CGMCC), together with Lxc ATCC 33973, L. aquatica ATCC 14665, and L. shinshuensis (no. Bio83655) bought from the Beijing Baiou Bowei Biotechnology Co., Ltd. (China), together with a Chinese $L x x$ strain provided by Ying Guo (Fujian Institute of Subtropical Botany, Xiamen, China). In addition, two causal bacterial pathogens in sugarcane, Acidovorax avenae subsp. avenae (SC-026) (Li et al. 2018) causing red stripe disease and Xanthomonas albilineans (Xa-FJ1) (Lin et al. 2018) associated with leaf scald disease were also tested.

DNA extraction. Total DNA was extracted from sugarcane leaf samples using the cetyl trimethylammonium bromide (CTAB) method (Haible et al. 2006). Bacterial genomic DNA was extracted using a Bacterial Genomic DNA Extraction Kit (Tiangen Biotech, Beijing, China) following the manufacturer's instructions. All DNA samples were eluted in $50 \mu \mathrm{l}$ sterile water and stored at $-20^{\circ} \mathrm{C}$. DNA quality was analyzed using $1 \%$ agarose gel electrophoresis and DNA concentration was measured with a Synergy H1 Hybrid Multi-Mode Reader (BioTek, Winooski, VT). All leaf DNA samples were diluted into a working concentration of $100 \mathrm{ng} / \mu \mathrm{l}$.

Primer design and PCR amplification. A novel $L x x$-specific primer pair, Lxx-F1 and Lxx-R1, was designed in this study using Primer Premier 6 software based on the ITS region between $16 \mathrm{~S}$ and 23S rRNA. In addition, two pairs of published $L x x$-specific primers, Cxx1/Cxx2 (Pan et al. 1998) and CxxITSf\#5/CxxITSr\#5 (Fegan et al. 1998), and one universal Leifsonia-specific primer pair, LayF/LayR (Young and Nock 2017) were used; these primers also target the ITS region of 16S-23S rRNA. Two other $L x x$-specific primer pairs, Pat1-F2/Pat1-R2 (Fu et al. 2016) targeting the unique pathogenicity gene-1 (Pat1) gene and $\mathrm{C} 2 \mathrm{~F} / \mathrm{C} 2 \mathrm{R}$ (Taylor et al. 2003) targeting a genomic fragment, were also used. All primers are listed in Table 1. PCR amplification was carried out in a $25 \mu \mathrm{l}$ mixture containing $1 \mu \mathrm{l}$ DNA (100 ng/ $\mu \mathrm{l}), 2.5 \mu \mathrm{l}$ of $10 \times \mathrm{Ex}$ Taq Buffer, $0.2 \mathrm{mM}$ of dNTPs, $0.4 \mu \mathrm{M}$ of each of the upstream and downstream primers, and $1.25 \mathrm{U}$ of $E x$ Taq. PCR was performed using the following protocol: $94^{\circ} \mathrm{C}$ for $3 \mathrm{~min}, 35$ cycles at $94^{\circ} \mathrm{C}$ for $30 \mathrm{~s}, 56^{\circ} \mathrm{C}$ (Cxx1/Cxx2), $55^{\circ} \mathrm{C}$ (CxxITSf\#5/CxxITSr\#5), 50 ${ }^{\circ} \mathrm{C}$ (Pat1-F2/Pat1$\mathrm{R} 2), 58^{\circ} \mathrm{C}$ (LayF/LayR), $62^{\circ} \mathrm{C}$ (Lxx-F1/Lxx-R1), or $60^{\circ} \mathrm{C}(\mathrm{C} 2 \mathrm{~F} /$ $\mathrm{C} 2 \mathrm{R}$ ) for $30 \mathrm{~s}$ and $72^{\circ} \mathrm{C}$ for $60 \mathrm{~s}$, with a final extension step at $72^{\circ} \mathrm{C}$ for $10 \mathrm{~min}$. Five microliter PCR products plus $1 \mu \mathrm{l}$ loading buffer were mixed together and then were resolved by 2 to $3 \%$ agarose gel electrophoresis, stained with ethidium bromide $(0.5 \mu \mathrm{g} /$ liter), and visualized on a UV transilluminator (JS-680D, Shang Hai Peiqing Science and Technology Corporation, China).

PCR sensitivity assays. To test the sensitivity of the six pairs of primers, a series of 10-fold dilutions of $L x x$ genomic DNA $(10 \mathrm{ng} / \mu \mathrm{l}$ to $1 \mathrm{fg} / \mu \mathrm{l})$ were used as templates and detected by conventional PCR in parallel. Moreover, to assess the gel-based specificity of the six pairs of primers, bacterial genomic DNA (10 ng) of $L x x$, Lxc, L. ginsengi, L. poae, L. rubra, L. aquatica, and L. shinshuensis were tested. Total DNA was extracted from an $L x x$-free leaf of FN0912206 or FN11-2097 clone and used as a negative control. Sterile water was used as a blank control. PCR products were analyzed using $2.0 \%$ agarose gel electrophoresis. All tests were performed in three independent experiments.

Field leaf sample detection and DNA sequencing. A total of 531 leaf samples from fields were examined using the six PCR assays with the above-mentioned primer pairs (Cxx1/Cxx2, CxxITSf\#5/ CxxITSr\#5, C2F/C2R, Pat1-F2/Pat1-R2, LayF/LayR, and Lxx-F1/ Lxx-R1). All PCR-positive products were purified using the Gel Extraction Kit (Omega Bio-Tek Inc., U.S.A.) following the manufacturer's instructions. The purified PCR products were ligated into vector pMD19-T (TaKaRa, Dalian, China). Three individual E. coli $\mathrm{DH} 5 \alpha$ colonies for each fragment were picked up and then sequenced bidirectionally with forward primer M13F (-47) and reverse primer M13F (-48) by Biosune Biotechnology Company (Fuzhou, China). Thus, six reads from each fragment were obtained, but only one sequence was retained for further sequence analysis if all reads shared $100 \%$ nucleotide sequence identity.

DNA sequence analysis. To verify the authenticity of PCR products, all sequences of PCR products were compared with those deposited in the National Center for Biotechnology Information (NCBI) library using the BLAST algorithm (https://www.ncbi.nlm. nih.gov/genbank/) online. A total of 19 DNA sequences amplified by the primers LayF/LayR in this study have been deposited in the GenBank database (Supplementary Table S1). A sequence dataset of these 19 DNA sequences and the corresponding sequences of 44 strains of Leifsonia derived from GenBank was used to investigate the bacterial population of Leifsonia strains. These sequences (approximately $600 \mathrm{bp}$ ) located in the ITS region of $16 \mathrm{~S}-23 \mathrm{~S}$ rRNA were aligned using MUSCLE as implemented in MEGA 6 (Tamura et al. 2013) with some manual adjustment. The best-fitting nucleotide substitution model was determined using the 'Find the best DNA/ protein models' option of MEGA6 software and a maximum likelihood phylogenetic tree was constructed using the T92+G model and the robustness of the tree topology was assessed with 1,000 bootstrap replicates. Clavibacter michiganensis subsp. insidiosus (GenBank accession no. KACC20766) was used as an outgroup sequence, and branches with bootstrap value $<60 \%$ were collapsed. Subsequently, pairwise sequence identities of the nucleotide sequences among these Leifsonia strains were calculated by BioEdit version 7.1.9 (Hall 1999).

\section{Results}

Sensitivity of six PCR assays. Serial concentrations of $L x x$ genomic DNA ranging from $10 \mathrm{ng} / \mu \mathrm{l}$ to $1 \mathrm{fg} / \mu \mathrm{l}$ were used to assess the sensitivity of six pairs of primers. The expected product sizes were 
observed for primers Lxx-F1/Lxx-R1 (439 bp), Cxx1/Cxx2 (439 bp), CxxITSf\#5/CxxITSr\#5 (305 bp), C2F/C2R (520 bp), Pat1-F2/Pat1R2 (597 bp), and LayF/LayR (642 bp) (Fig. 1). Conventional PCR results revealed that the minimum detection limits were $1 \mathrm{pg} / \mu \mathrm{l}$ for three primer pairs Lxx-F1/Lxx-R1 (Fig. 1A), Cxx1/Cxx2
(Fig. 1B), and CxxITSf\#5/CxxITSr\#5 (Fig. 1C), and $10 \mathrm{pg} / \mu \mathrm{l}$ for primer pairs C2F/C2R (Fig. 1D), Pat1-F2/Pat1-R2 (Fig. 1E), and LayF/LayR (Fig. 1F).

Specificity of six PCR assays. All six pairs of primers were evaluated for their specificity using nine bacterial genomic DNA samples

Table 1. List of six primer pairs

\begin{tabular}{|c|c|c|c|c|c|}
\hline Primer & Sense & Sequence $\left(5^{\prime}-3^{\prime}\right)$ & Gene targeted & Amplicon size (bp) & Reference \\
\hline Lxx-F1 & Forward & CCGAAGTGAGCAGATTGACCAATGAT & ITS & 439 & This study \\
\hline Lxx-R1 & Reverse & ACCCTGTGTTGTTTTCAACGCAGAG & & & \\
\hline Cxx1 & Forward & CCGAAGTGAGCAGATTGACC & ITS & 439 & Pan et al. 1998 \\
\hline $\mathrm{Cxx} 2$ & Reverse & ACCCTGTGTTGTTTTCAACG & & & \\
\hline CxxITSf\#5 & Forward & TCAACGCAGAGATTGTCCA & ITS & 305 & Fegan et al. 1998 \\
\hline CxxITSr\#5 & Reverse & GTACGGGCGGTACCTTTTC & & & \\
\hline $\mathrm{C} 2 \mathrm{~F}$ & Forward & CGAGTTTGGGTTTCTGCCTGC & Genomic fragment & 520 & Taylor et al. 2003 \\
\hline $\mathrm{C} 2 \mathrm{R}$ & Reverse & AGGTGGCAGCGACAACGGTGC & & & \\
\hline Pat1-F2 & Forward & GGAATACTCGCTATGTGTTG & Pat1 & 597 & Fu et al. 2016 \\
\hline Pat1-R2 & Reverse & CCAATACTATGCCGTAGAAAG & & & \\
\hline LayF & Forward & AAGGAGCATCTGGCACCC & ITS & 642 & Young and Nock 2017 \\
\hline LayR & Reverse & GGGAGTCACTGGGTCACC & & & \\
\hline
\end{tabular}
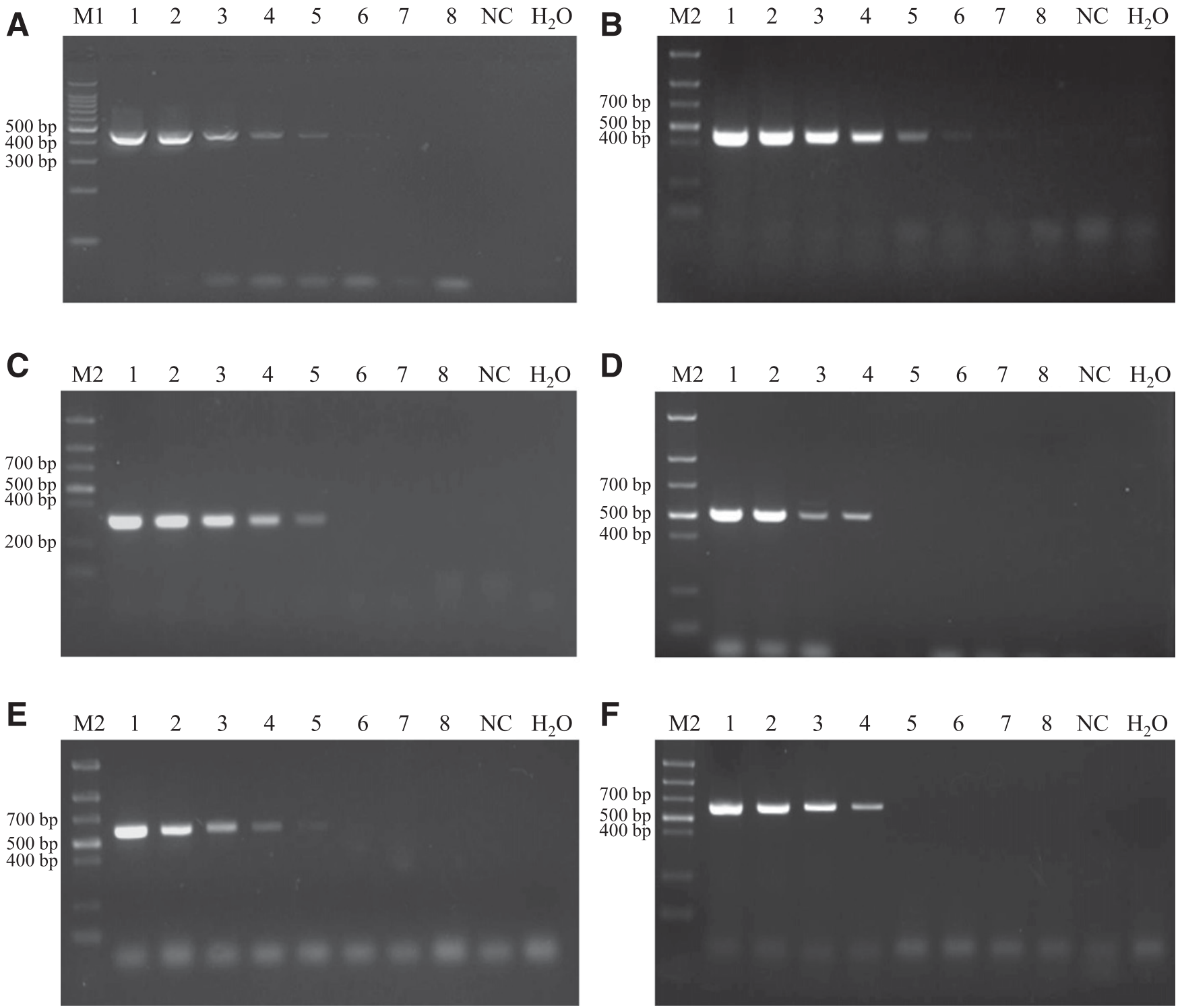

Fig. 1. 2.0\% agarose gel-based sensitivity was tested using the six pairs of primers with conventional PCR. The 10-fold dilution templates ranged from $10 \mathrm{ng} / \mu \mathrm{l}$ to $1 \mathrm{fg} / \mu \mathrm{l}(\mathrm{lanes} 1-8)$ of genomic DNA of Leifsonia xyli subsp. xyli (Lxx) was used for primers, Lxx-F1/Lxx-R1 (A), Cxx1/Cxx2 (B), CxxITSA\#5/CxxITSI\#5 (C), C2F/C2R (D), Pat1-F2/Pat1-R2 (E), and LayF/LayR (F). M1, 100 bp DNA ladder; M2, Trans DNA Marker II; NC, total DNA (100 ng) extracted from a Lxx-free leaf sample of Saccharum spp. clone FN09-12206 (A-E) or FN11-2097 (F). 
(10 ng) originating from Leifsonia spp. isolates including $L x x, L x c, L$. ginsengi, L. poae, L. rubra, L. aquatica, and $L$. shinshuensis as well as from two other sugarcane disease pathogens, A. avenae subsp. avenae and $X$. albilineans. Four pairs of primers $(\mathrm{Cxx} 1 / \mathrm{Cxx} 2$, Pat1-F2/Pat1-R2, CxxITSf\#5/CxxITSr\#5, and Lxx-F1/Lxx-R1) were specific for $L x x$ and generated the individual expected amplification products and did not produce amplicons in the other six bacterial genomic DNA samples of Leifsonia species. However, in addition to $L x x$ genomic DNA, C2F/C2R primers amplified the two bands (482 bp and $515 \mathrm{bp}$ ) of genomic DNA of L. aquatica (Table 2). The universal primer pair LayF/LayR amplified the expected bands in genomic DNA of all tested Leifsonia species. As expected, no bands were amplified by these six pairs of primers in two causal pathogens of sugarcane, $X$. albilineans and $A$. avenae subsp. avenae (Table 2).

Comparison of six PCR assays in field samples. Among 531 collected leaf samples, $33(6.2 \%)$ of them were positive using the primer pair Lxx-F1/Lxx-R1 and generated one fragment with the expected size (439 bp); whereas 3.8\% (20/531), 3.0\% (16/531), $1.7 \%$ (9/531), $1.3 \%(7 / 531)$, and $1.9 \%$ (10/531) of leaf samples were positive using the primers $\operatorname{Cxx} 1 / \mathrm{Cxx} 2$ (439 bp), CxxITSf\#5/ CxxITSr\#5 (305 bp), C2F/C2R (520 bp), LayF/LayR (642 bp), and Pat1-F2/Pat1-R2 (597 bp), respectively (Table 3).

Unexpectedly, the $\mathrm{Cxx} 1 / \mathrm{Cxx} 2$ primers generated two major nonspecific fragments (about $400 \mathrm{bp}$ and $350 \mathrm{bp}$ ). In particular, bands $\sim 400$ bp were commonly nonspecifically amplified (Supplementary Fig. S1). The LayF/LayR primers produced at least four major nonspecific fragments, including $800-1,700 \mathrm{bp}$, as well as approximately $600 \mathrm{bp}, 400 \mathrm{bp}$, and $300 \mathrm{bp}$. Notably, the $\sim 600 \mathrm{bp}$ nonspecific fragments were easily amplified in the leaf samples of germplasm clones, especially E. arundinaceus (Supplementary Fig. S2). Thus, nonspecific amplifications occurred in PCR assays with $\mathrm{Cxx} 1 / \mathrm{Cxx} 2$ and LayF/LayR primers, accounting for $44.1 \%$ $(234 / 531)$ in all tested samples and $11.1 \%(24 / 216)$ in germplasm clones.

Sequence analysis of PCR amplicons. Based on the cloning and sequencing of $L x x$-positive PCR products, all expected sequences of $L x x$ fragments generated from six primer pairs shared $100 \%$ nucleotide sequence identity and also $100 \%$ homology to the published Lxx isolate CTCB07 (GenBank accession AE016822). Furthermore, 75 and 22 representative nonspecific fragments amplified by Cxx1/Cxx2 and LayF/LayR were also cloned and sequenced, respectively (Fig. 2). Sequence BLASTing online revealed that 135 sequences amplified by primers $\mathrm{Cxx} 1 / \mathrm{Cx} 2$ in Saccharum and $E$. arundinaceus clones shared high nucleotide identity (85.7-98.8\%) with genomic sequence of $S$. spontaneum (GenBank accession no. UINE01054449). In addition, 45 sequences amplified by primers LayF/LayR in germplasms of Saccharum species and E. arundinaceus shared $76.0-97.2 \%$ nucleotide identity with genomic sequence of $S$. spontaneum.

Table 2. Specificity tests of six PCR assays with five primer pairs for Leifsonia xyli subsp. xyli $(L x x)$ and one universal primer pair for Leifsonia species ${ }^{\mathrm{a}}$

\begin{tabular}{|c|c|c|c|c|c|c|}
\hline Strain/isolate & Lxx-F1/Lxx-R1 & $\operatorname{Cxx1/Cxx2}$ & CxxITSf\#5/CxxITSr\#5 & $\mathrm{C} 2 \mathrm{~F} / \mathrm{C} 2 \mathrm{R}$ & Pat1-F2/Pat1-R2 & LayF/LayR \\
\hline$L x x$ & + & + & + & + & + & + \\
\hline$L x c$ & - & - & - & - & - & + \\
\hline L. poae & - & - & - & - & - & + \\
\hline L. rubra & - & - & - & - & - & + \\
\hline L. ginsengi & - & - & - & - & - & + \\
\hline L. aquatica & - & - & - & + & - & + \\
\hline L. shinshuensis & - & - & - & - & - & + \\
\hline Acidovorax avenae subsp. avenae & - & - & - & - & - & - \\
\hline Xanthomonas albilineans & - & - & - & - & - & - \\
\hline
\end{tabular}

a “+”, positive results; “-”, negative results.

Table 3. Incidences of Leifsonia xyli subsp. xyli $(L x x)$ in sugarcane leaf samples detected by conventional PCR ${ }^{\mathrm{a}}$

\begin{tabular}{|c|c|c|c|c|}
\hline Primer pairs & Sample origins & $\begin{array}{c}\text { No. of leaf } \\
\text { sample tested }\end{array}$ & $\begin{array}{l}\text { No. of positive } \\
\text { samples }\end{array}$ & $\begin{array}{c}\text { Percentage of } \\
\text { positive samples }\end{array}$ \\
\hline Lxx-F1/Lxx-R1 & Guizhou & 80 & 3 & 3.8 \\
\hline Lxx-F1/Lxx-R1 & Sichuan & 122 & 4 & 3.3 \\
\hline Lxx-F1/Lxx-R1 & Yunnan & 113 & 22 & 19.5 \\
\hline Lxx-F1/Lxx-R1 & Hainan & 216 & 4 & 1.9 \\
\hline $\mathrm{Cxx} 1 / \mathrm{Cxx} 2$ & Guizhou & 80 & $0(50)$ & $0(62.5)$ \\
\hline $\mathrm{Cxx} 1 / \mathrm{Cxx} 2$ & Sichuan & 122 & $1(90)$ & $0.8(73.8)$ \\
\hline $\mathrm{Cxx} 1 / \mathrm{Cxx} 2$ & Yunnan & 113 & $17(31)$ & $15.0(27.4)$ \\
\hline $\mathrm{Cxx} 1 / \mathrm{Cxx} 2$ & Hainan & 216 & $2(63)$ & $0.9(29.2)$ \\
\hline CxxITSf\#5/CxxITSr\#5 & Guizhou & 80 & 1 & 1.3 \\
\hline CxxITSf\#5/CxxITSr\#5 & Sichuan & 122 & 2 & 1.6 \\
\hline CxxITSf\#5/CxxITSr\#5 & Yunnan & 113 & 11 & 9.7 \\
\hline CxxITSf\#5/CxxITSr\#5 & Hainan & 216 & 2 & 0.9 \\
\hline $\mathrm{C} 2 \mathrm{~F} / \mathrm{C} 2 \mathrm{R}$ & Guizhou & 80 & 1 & 1.3 \\
\hline $\mathrm{C} 2 \mathrm{~F} / \mathrm{C} 2 \mathrm{R}$ & Sichuan & 122 & 1 & 0.8 \\
\hline $\mathrm{C} 2 \mathrm{~F} / \mathrm{C} 2 \mathrm{R}$ & Yunnan & 113 & 7 & 6.2 \\
\hline $\mathrm{C} 2 \mathrm{~F} / \mathrm{C} 2 \mathrm{R}$ & Hainan & 216 & 0 & 0 \\
\hline Pat1-F2/Pat1-R2 & Guizhou & 80 & 2 & 2.5 \\
\hline Pat1-F2/Pat1-R2 & Sichuan & 122 & 1 & 0.8 \\
\hline Pat1-F2/Pat1-R2 & Yunnan & 113 & 5 & 4.4 \\
\hline Pat1-F2/Pat1-R2 & Hainan & 216 & 2 & 0.9 \\
\hline LayF/LayR & Guizhou & 80 & 2 & 2.5 \\
\hline LayF/LayR & Sichuan & 122 & 0 & 0 \\
\hline LayF/LayR & Yunnan & 113 & 3 & 2.7 \\
\hline LayF/LayR & Hainan & 216 & $2(24)$ & $0.9(11.1)$ \\
\hline
\end{tabular}

${ }^{a}$ The number and percent (\%) of nonspecific amplification samples are shown in parentheses. 
Phylogenetic analysis of various Leifsonia strains. Twelve sequences (576-595 bp) representing distinct Leifsonia strains and seven sequences of $L x x$ pathogen were obtained from sugarcane leaf samples by PCR assay using Leifsonia generic primers LayF/LayR in this study. Based on the classification and annotation of phylogenetic groups (Leifsonia strains and non-Leifsonia strains) and genotypes within groups proposed by Young and Nock (2017), phylogenetic analysis revealed that all sequences obtained in this study were clustered into two phylogenetic clades, namely, Leifsonia group (L) and non-Leifsonia group (N) (Fig. 3). The Leifsonia group was further subdivided into 10 distinct genotypes (L1b, L1f, L2a, L2c, L2d, L3b, L4c, L4d, L5g, and Lxx), including all 19 Leifsonia sequences obtained in this study. Of the 10 genotypes, we proposed seven novel genotypes, namely L1f (sample YN4 and YN8), L2c (sample YN6), L2d (sample SC3 and SC4), L3b (sample YN11), L4c (sample YN9), L4d (sample YN10), and L5g (sample YN2).

Nucleotide sequence identity analysis of various Leifsonia strains. Pairwise sequence identity revealed that seven novel genotypes (L1f, L2c, L2d, L3b, L4c, L4d, and L5g) respectively had 96.0-99.8\%, $98.7-99.0 \%, 99.2 \%, 98.1 \%, 92.4-95.0 \%, 96.0-99.0 \%$, and 91.4-99.6\% nucleotide sequence identities compared with the published isolates in each of the Leifsonia groups (Supplementary Table S2). Two sequences (sample SC1 and sample SC2) obtained in this study belonged to L1b genotype and shared $100 \%$ homology with the published sequence of LSB13-028 (GenBank accession KY352962); another sequence (sample YN5) obtained in this study belonged to L2a genotype and showed $100 \%$ homology with the published sequence of LSB14-197 (GenBank accession KY352968); and seven sequences (samples YN1, YN3, YN7, HNEa1, HNSo1, GZ1, and GZ2) obtained in this study clustered in the $L x x$ group showed $100 \%$ identity with $L x x$ isolate CTCB07 (GenBank accession AE016822).

\section{Discussion}

Diverse $L x x$-specific primers have been developed and used in RSD diagnosis. For example, two pairs of $L x x$-specific primers, Cxx1/Cxx2 (Pan et al. 1998) and CxxITSf5\#/CxxITSr5\# (Fegan et al. 1998), and one universal pair of Leifsonia-specific primers, LayF/LayR (Young and Nock 2017), were designed to target the ITS region of $16 \mathrm{~S}-23 \mathrm{~S}$ rRNA. Additionally, three pairs of $L x x$ specific primers, namely Pat1-F2/Pat1-R2 (Fu et al. 2016), FL12650F2/FL12650R2 (Zavaglia et al. 2016), and C2F/C2R (Taylor et al. 2003) were designed to target the $L x x$ strain CTCBO7 genome (GenBank accession no. AE016822), including unique gene Lxx24245 (locus_tag = "Lxx12650", encoding pathogenicity gene-1, Pat1), Lxx12650 (locus_tag = "Lxx12650", encoding a hypothetical protein), and a gene fragment (at genomic position from nucleotide 1434553 to 1435073 ) to detect this pathogen, respectively. Among the published primer pairs for PCR assays, the primer pair Cxx1/ $\mathrm{Cxx} 2$ has been widely used, but we found nonspecific amplification from sugarcane tissue-extracted DNA samples using this primer pair during our practice RSD diagnosis. Hence, we developed a novel $L x x$-specific primer pair, Lxx-F1 and Lxx-R1, for pathogen detection in numerous leaf samples from different host plants including Saccharum spp. hybrid, five Saccharum species, and E. arundinaceus.

Our findings revealed that Lxx-F1 and Lxx-R1 had higher effectiveness compared with the other five tested primer pairs during the field sample diagnostic comparison, even though Lxx-F1/LxxR1 primers shared the same minimum detection limits $(1 \mathrm{pg} / \mu \mathrm{l})$ of bacterial genomic DNA with two pairs of primers, $\operatorname{Cxx} 1 / \operatorname{Cxx} 2$ and CxxITSf\#5/CxxITSr\#5. The same sensitivity (1 pg/ $\mu$ l) was reported for PCR detection of $L x x$ genomic DNA using primers Cxx1/Cxx2 (Pan et al. 1998) and FL12650F2/FL12650R2 (Zavaglia et al. 2016). Furthermore, a similar detection threshold of $10^{3}$ cells $/ \mathrm{ml}$ was shown in the PCR detection of $L x x$ bacterial cells using primers CxxITSf\#5/CxxITSr\#5 (Fegan et al. 1998) and C2F/C2R (Taylor et al. 2003).

Primer specificity is one of the most important aspects for the detection of causal pathogens using PCR methods. The genus Leifsonia is part of the family Microbacteriaceae, which comprises 11 species and two subspecies isolated from very diverse environments and can be associated with plants, animals, and clinical specimens
$\mathbf{A}$
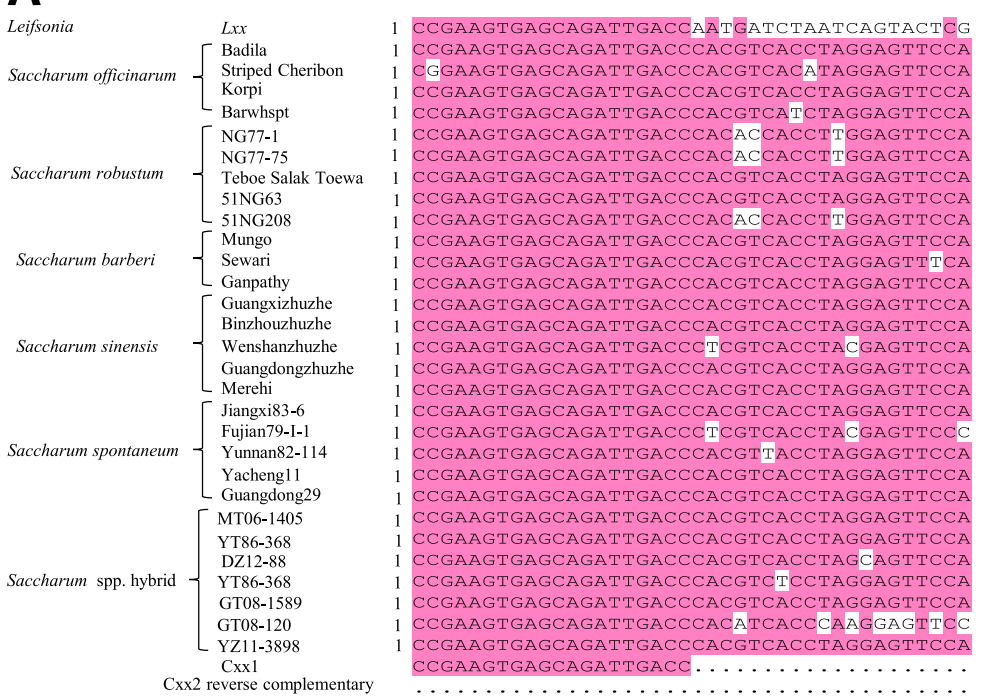

B

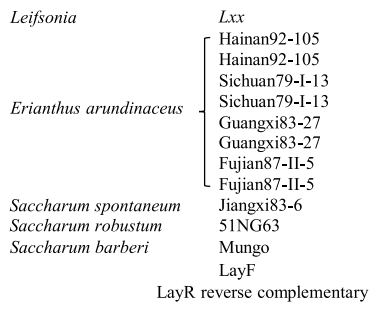

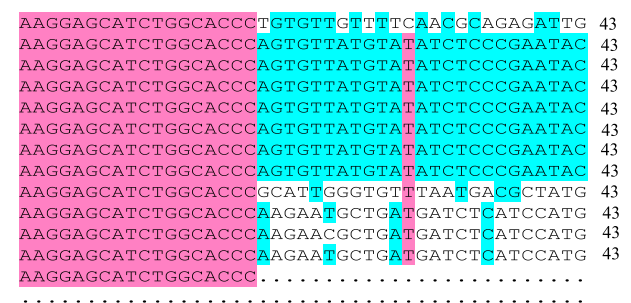
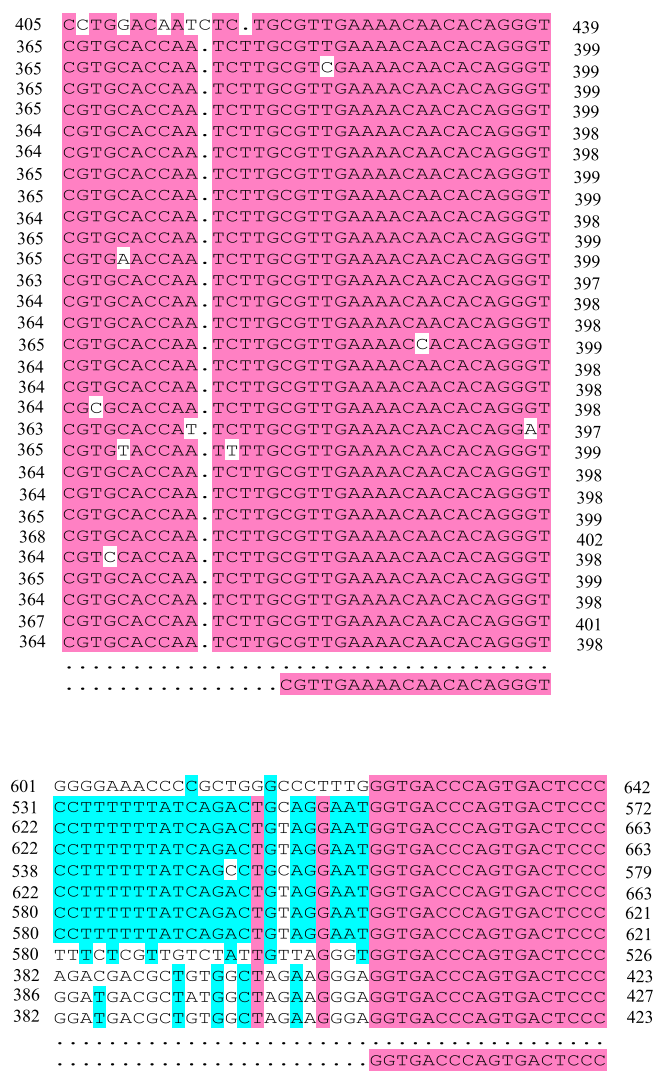

Fig. 2. Multiple sequence alignment among Leifsonia xyli subsp. xyli (Lxx) sequence and sugarcane genomic sequences amplified by $C x x 1 / C x x 2$ (A) and LayF/LayR (B). 
(Evtushenko 2015). L. xyli is the only plant pathogenic species of the genus described to date, and it comprises two subspecies: $L x x$, causing RSD in sugarcane (Davis et al. 1984), and Lxc, a pathogen of bermudagrass (Cynodon dactylis) (Zavaglia et al. 2016). Apart from $L x x$, one Leifsonia subspecies $(L x c)$ and five Leifsonia species $(L$. ginseng, L. poae, L. rubra, L. aquatica, and L. shinshuensis) were

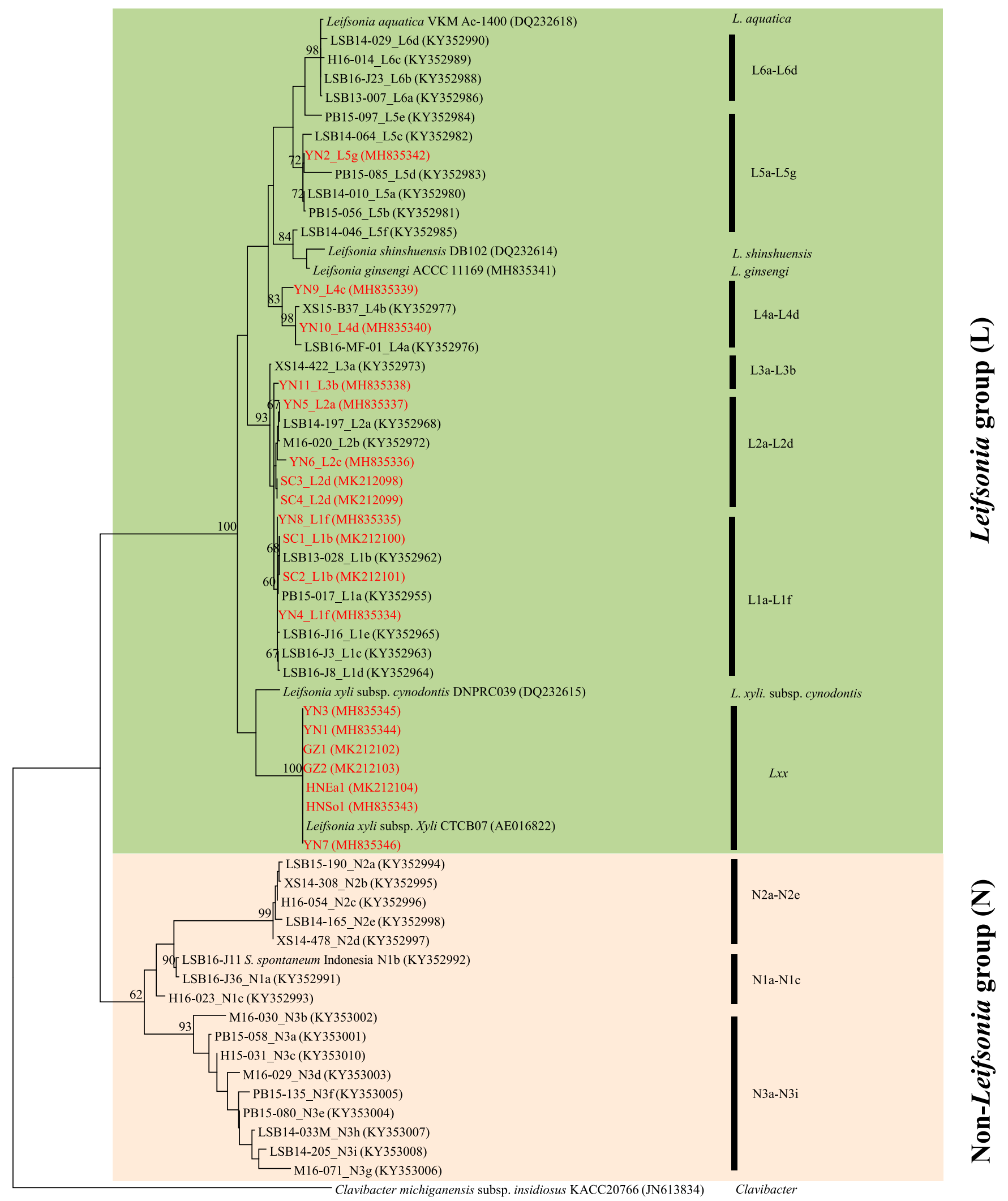

0.1

Fig. 3. The phylogenetic tree was constructed in MEGA6 using maximum-likelihood method based on 16S-23S rRNA internal transcribed spacer (ITS) sequences amplified by the primers LayF/LayR from 19 Chinese Leifsonia strains (with red color) in this study and 44 corresponding sequences of representative Leifsonia and non-Leifsonia strains obtained in Young and Nock (2017). Clavibacter michiganensis subsp. insidiosus (GenBank accession no. KACC20766) was used as an outgroup sequence. The robustness of the tree topology was assessed with 1,000 bootstrap replicates and branches with bootstrap value $<60 \%$ were collapsed. 
employed for the specificity tests of PCR assays in this study. Of seven tested species of Leifsonia, the type species L. aquatica together with $L x x, L x c, L$. poae, and $L$. shinshuensis come from a coherent cluster (Leifsonia sensu stricto species group) based on phylogenetic grouping of the 16S rRNA gene sequences, whereas two remaining species $L$. ginseng and $L$. rubra come from separate lineages outside the coherent Leifsonia sensu stricto species group (Evtushenko 2015). Specificity tests suggested that, except LayF/ LayR and $\mathrm{C} 2 \mathrm{~F} / \mathrm{C} 2 \mathrm{R}$ primers, four other primer pairs were specific for $L x x$.

Based on field sample diagnostic comparison of six primer pairs, nonspecific amplifications were generated by the primer pair $\mathrm{Cxx} 1 /$ $\mathrm{Cxx} 2$ in Saccharum and E. arundinaceus clones, which revealed that this pair of primers could amplify related fragments ( $\sim 400 \mathrm{bp})$ in the sugarcane genome. In this case, nonspecific amplification and truepositive PCR products can be easily confused because of their slightly different amplified band sizes ( 400 bp vs. 439 bp) in low concentrated $(<2 \%)$ agarose gels. Recently, the universal generic primers LayF and LayR were used for detection of Leifsonia strains (Young and Nock 2017). However, this pair of primers also produced nonspecific amplification among germplasms of Saccharum and E. arundinaceus. Sequencing of some representative nonspecific fragments (300-1,700 bp) amplified by the primers LayF/LayR show that these sequences belonged to sugarcane genomic fragments. Collectively, the primer pairs $\mathrm{Cxx} 1 / \mathrm{Cxx} 2$ and LayF/LayR would not be adequate for RSD diagnosis and $L x x$ detection by PCR assays in sugarcane leaf samples. We attempted to optimize the PCR component or PCR cycling conditions to overcome nonspecific amplification in some sugarcane leaf samples but failed to improve two primer pairs (data not shown).

The universal primer pair LayF/LayR can amplify other novel Leifsonia or non-Leifsonia strains in sugarcane (Young and Nock 2017). These putative Leifsonia strains could not be isolated from leaf sheath biopsy or expressed xylem sap and even a non-Leifsonia bacterium producing RSD-like internal symptoms in basal nodes was not successfully isolated, excluding artifacts due to the environment or sample processing (Young and Nock 2017). We also obtained sequences of seven novel Leifsonia strains and three published genotypes, $L x x$, L2a, and L1b, which were generated by the primers LayF/LayR. These novel Leifsonia strains came from Lincang and Dehong, Yunnan province, and Neijiang, Sichuan province, China. However, it is necessary to confirm that the novel Leifsonia strains are either pathogenic to sugarcane or whether they are endophyte bacteria. No non-Leifsonia strains were identified in our samples.

In conclusion, the novel primer pair Lxx-F1 and Lxx-R1 was successfully developed for $L x x$ detection in field leaf samples with satisfactory sensitivity, specificity, and efficiency. Also, the two primer pairs CxxITSf\#5/CxxITSr\#5 and Pat1-F2/Pat1-R2 could be used for routine testing of sugarcane for RSD, but they had less $L x x$-positive detection compared with Lxx-F1/Lxx-R1 primers. By contrast, the $L x x$-specific primers $\mathrm{Cxx} 1 / \mathrm{Cxx} 2$ should be carefully used for RSD diagnosis because these primers amplified nonspecific fragments in leaf tissues that were collected from modern sugarcane cultivar, Saccharum species, and E. arundinaceus. The Cxx1/Cxx2 primers could be utilized for $L x x$ detection in bacterial purecultured cells, vascular sap (Pan et al. 1998), or pooled leaf sheath biopsies (Young et al. 2016; Young and Nock 2017), rather than in sugarcane plant tissues. The $\mathrm{C} 2 \mathrm{~F} / \mathrm{C} 2 \mathrm{R}$ primers could be used for $L x x$ detection and discriminating $L x x$ from $L x c$ and $L$. $x y l i$-like bacteria (Taylor et al. 2003), but our findings revealed that these primers could produce amplification product from the template of genomic DNA of L. aquatica that inhabits environmental water (Evtushenko 2015). The Leifsonia-generic primers LayF/LayR could be employed for molecular detection of diverse Leifsonia strains associated with sugarcane using expressed xylem sap or pooled leaf sheath biopsies (Young and Nock 2017).

\section{Literature Cited}

Carvalho, G., Da Silva, T. G. E. R., Munhoz, A. T., Monteiro-Vitorello, C. B., Azevedo, R. A., Melotto, M., and Camargo, L. E. A. 2016. Development of a qPCR for Leifsonia xyli subsp. xyli and quantification of the effects of heat treatment of sugarcane cuttings on Lxx. Crop Prot. 80:51-55.

Comstock, J. C., Shine, J. M. J., Davis, M. J., and Dean, J. L. 1996 Relationship between resistance to Clavibacter xyli subsp. xyli colonization in sugarcane and spread of ratoon stunting disease in the field. Plant Dis. 80:704-708.

Davis, M., Dean, J., Miller, J., and Shine, J. 1994. A method to screen for resistance to ratoon stunting disease of sugarcane. Sugar Cane 6:9-16.

Davis, M. J., Gillaspie Jr., A. G., Vidaver, A. K., and Harris, R. W. 1984 Clavibacter: a new genus containing some phytopathogenic coryneform bacteria, including Clavibacter xyli subsp. xyli sp. nov., subsp. nov. and Clavibacter xyli subsp. cynodontis subsp. nov., pathogens that cause ratoon stunting disease of sugarcane and Ber. Int. J. Syst. Bacteriol. 34:107-117.

Evtushenko, L. I. 2015. Leifsonia. Pages 1-32 in: Bergey's Manual of Systematics of Archaea and Bacteria. W. B. Whitman, ed. J. Wiley \& Sons, Ltd., Chichester, UK

Evtushenko, L. I., Dorofeeva, L. V., Subbotin, S. A., Cole, J. R., and Tiedje, J. M 2000. Leifsonia poae gen. nov., sp. nov., isolated from nematode galls on Poa annua, and reclassification of 'Corynebacterium aquaticum' Leifson 1962 as Leifsonia aquatica (ex Leifson 1962) gen. nov., nom. rev., comb. nov. and Clavibacter xyli Davis et al. 1984 with two subspecies as Leifsonia xyli (Davis et al. 1984) gen. nov., comb. nov. Int. J. Syst. Evol. Microbiol. 50: 371-380.

Farahani, A. S., Taghavi, S. M., and Taherkhani, K. 2015. Comparison of conventional, nested and real-time PCR for detection of the causal agent of ratoon stunt in Iran. J. Plant Pathol. 97:259-263.

Fegan, M., Croft, B., Teakle, D., Hayward, A., and Smith, G. 1998. Sensitive and specific detection of Clavibacter xyli subsp. xyli, causal agent of ratoon stunting disease of sugarcane, with a polymerase chain reaction-based assay. Plant Pathol. 47:495-504.

Fu, H. Y., Sun, S. R., Wang, J. D., Ahmad, K., Wang, H. B., Chen, R. K., and Gao, S. J. 2016. Rapid and quantitative detection of Leifsonia xyli subsp. xyli in sugarcane stalk juice using a real-time fluorescent (TaqMan) PCR assay. BioMed Res. Int. 2016:1-8

Gao, S. J., Pan, Y. B., Chen, R. K., Chen, P. H., and Zhang, H. 2008. Quick detection of Leifsonia xyli subsp. xyli by PCR and nucleotide sequence analysis of PCR amplicons from Chinese Leifsonia xyli subsp. xyli isolates. Sugar Tech 10:334-340.

Ghai, M., Singh, V., Martin, L. A., Mcfarlane, S. A., Antwerpen, T. V., and Rutherford, R. S. 2014. A rapid and visual loop-mediated isothermal amplification assay to detect Leifsonia xyli subsp. xyli targeting a transposase gene. Lett. Appl. Microbiol. 59:648-657.

Gillaspie Jr., A. G., and Teakle D. S. 1989. Ratoon stunting disease. Pages 59-80 in: Disease of Sugarcane: Major Disease. C. Ricaud, B. T. Egan, A. G. Gillaspie Jr. and C. G. Hughes, eds. Elsevier Science, New York.

Grisham, M. P., Pan, Y. B., and Jr. Richard, E. P. 2007. Early detection of Leifsonia xyli subsp. xyli in sugarcane leaves by real-time polymerase chain reaction. Plant Dis. 91:430-434.

Haible, D., Kober, S., and Jeske, H. 2006. Rolling circle amplification revolutionizes diagnosis and genomics of geminiviruses. J. Virol. Methods 135:9-16

Hall, T. A. 1999. BioEdit: a user-friendly biological sequence alignment editor and analysis program for Windows 95/98/NT. Nucl. Acids. Symp. Ser. 41:95-98.

Harrison, N. A., and Davis, M. J. 1990. Comparison of serological techniques for diagnosis of ratoon stunting disease. Sugar Cane (Spring Supplement):5-9.

Hoy, J. W., Grisham, M. P., and Damann, K. 1999. Spread and increase of ratoon stunting disease of sugarcane and comparison of disease detection methods. Plant Dis. 83:1170-1175.

Li, X. Y., Sun, H. D., Rott, P. C., Wang, J. D., Huang, M. T., Zhang, Q. Q., and Gao, S. J. 2018. Molecular identification and prevalence of Acidovorax avenae subsp. avenae causing red stripe of sugarcane in China. Plant Pathol. 67:929-937.

Lin, L., Ntambo, M. S., Rott, P. C., Wang, Q., Lin, Y., Fu, H., and Gao, S. 2018 Molecular detection and prevalence of Xanthomonas albilineans, the causal agent of sugarcane leaf scald, in China. Crop Prot. 109:17-23.

Liu, J., Xu, L., Guo, J., Chen, R., Grisham, M. P., and Que, Y. 2013. Development of Loop-Mediated Isothermal Amplification for Detection of Leifsonia xyli subsp. xyli in Sugarcane. BioMed Res. Int. 2013:1-8

Martin, J. P., Abbott, E. V., and Hughes, E. G. 1982. Sugarcane Diseases of the World, Vol. 1. Q. L. Chen, translator. China Agriculture Press, Beijing, China.

Matthews, A. 1993. New method makes identification of RSD more efficient. BSES Bull. 44:16-17.

Mills, L., Leaman, T. M., Taghavi, S. M., Shackel, L., Dominiak, B. C. Taylor, P. W. J., Fegan, M., and Teakle, D. S. 2001. Leifsonia xyli -like bacteria are endophytes of grasses in eastern Australia. Australas. Plant Pathol. 30:145-151.

Pan, Y. B., Grisham, M. P., Burner, D. M., Damann, K. E., Jr., and Wei, Q. 1998. A polymerase chain reaction protocol for the detection of Clavibacter xyli subsp. xyli, the causal bacterium of sugarcane ratoon stunting disease. Plant Dis. 82:285-290.

Pelosi, C. S., Lourenço, M. V., Silva, M., Santos, A. Z., França, S. C., and Marins, M. 2013. Development of a Taqman real-time PCR assay for detection of Leifsonia xyli subsp xyli. Trop. Plant Pathol. 38:343-345. 
Shen, W. K., Liu, R., and Deng, H. H. 2012. Nested-PCR detection for Leifsonia $x y l i$ subsp $x y l i$, the causal bacterium of sugarcane ratoon stunting disease. Acta Phytophy. Sin. (Chinese) 39:508-512.

Tamura, K., Stecher, G., Peterson, D., Filipski, A., and Kumar, S. 2013. MEGA6: Molecular Evolutionary Genetics Analysis Version 6.0. Mol. Biol. Evol. 30:2725-2729.

Taylor, P. W. J., Petrasovits, L. A., Velde, R. V. D., Birch, R. G., Croft, B. J., Fegan, M., Smith, G. R., and Brumbley, S. M. 2003. Development of PCRbased markers for detection of Leifsonia xyli subsp. xyli in fibrovascular fluid of infected sugarcane plants. Australas. Plant Pathol. 32:367.

Wu, Q. B., Pan, Y. B., Zhou, D. G., Grisham, M. P., Gao, S. W., Su, Y. C., Guo, J. 1., Xu, L. P., and Que, Y. X. 2018. A comparative study of three detection techniques for Leifsonia xyli Subsp. xyli, the causal pathogen of sugarcane ratoon stunting disease. BioMed Res. Int. 2018:2786458.

Young, A. J., Kawamata, A., Ensbey, M. A., Lambley, E., and Nock, C. J. 2016. Efficient Diagnosis of ratoon stunting disease of sugarcane by quantitative PCR on pooled leaf sheath biopsies. Plant Dis. 100:2492-2498.

Young, A. J., and Nock, C. J. 2017. Molecular detection of diverse Leifsonia strains associated with sugarcane. Plant Dis. 101:1422-1431.

Zavaglia, A. C., Cia, M. C., Popin, R. V., and Camargo, L. E. A. 2016. No alternative hosts of the sugarcane pathogen Leifsonia xyli subsp. xyli were identified among grass and non-grass species using novel PCR primers. Trop. Plant Pathol. 41:336-339. 